\begin{tabular}{|c|c|c|}
\hline $\begin{array}{l}\text { An International Biannual Open Access } \\
\text { Peer-Reviewed/Refereed Journal } \\
\text { JOURNAL OF GLOBAL RESOURCES } \\
\text { Published by : ISDESR, Jaipur, India }\end{array}$ & 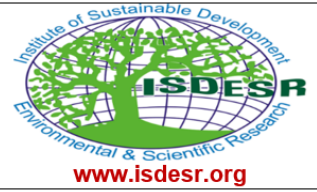 & $\begin{array}{r}\text { ISSN: 2395-3160 (Print) } \\
\text { ISSN: } 2455-2445 \text { (Online) } \\
\text { January 2022, Volume 08 (01) } \\
\text { DOI Prefix: } 10.46587 / \text { JGR }\end{array}$ \\
\hline
\end{tabular}

18

\title{
KALANA IS THE ONLY SOURCE OF CREATION AND SOURCE OF ENERGY IN THIS UNIVERSE
}

\author{
Jagadeesha
}

Assistant Engineer (Ele.), KPTCL, Thambrahalli, Vijayanagar, Karnataka, India Email: pjagadeesh.h.n@gmail.com

How to cite this paper:

Jagadeesha (2022) Kalana is the only source of creation and source of energy in this universe, Journal of Global Resources, Vol. 08 (01)

\section{DOI:}

10.46587/JGR.2022.v08i01.018

Received: 24 Oct. 2021

Reviewed: 05 Nov. 2021

Revised: 24 Nov. 2021

Final Accepted: 04 Dec. 2021

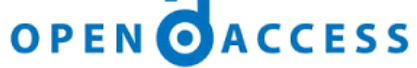

Freely available Online www.isdesr.org

\begin{abstract}
One side, most of the researches going on Universe, Space, Black holes, white holes, development of technology etc. and on the other side world is ending due to pollution. The transparent media, to which I'm calling as "Kalana", that exists during sunlight and disappears at night, is actually brighter then sunlight. But due to pollution, it is looking dark. Wherever pure Kalana exists, there sunlight or any other source of light or Energy have no value. As Pollution increase, darkness also increases and reduces the presence of Kalana. Kalana itself is the source of creation and source of Energy in this universe. Each and everything that exist in this universe is created from Kalana. The outcome of Universal arrangements in Kalana is called "truth". Truth has its own significant value in our society and everyone wish to be truthful for peaceful life. This is the main reason that, our ancestor was always tried to follow the truth and had advance technology then today what we have. Today's technologies are not based upon the principle of truth and hence everything has its own side effects.
\end{abstract}

Key words: Kalana, Truth, Black Hole, White Hole. 


\section{Introduction}

I'm witness for both modernisation and ancient civilisation. Observations and experiments conducted only around one village "Nagarahalli" before and after 2000, gave more practical evidence for Origin and Evolution of Universe as well as the End of life. 20years back there was no hospital in my village, but now it was there with good medical facilities. 20 years back there was no need of water filter to purify the drinking water, but today everyone wish to drink filtered water to take care of health. You can't say that, 20 years back there was no advanced technology. So, there was no good facilities. Actually, there was no much more health issues. 20 years back, people had good immunity and extremely high power in their muscles. Hence, most of the people spent their whole life without a single disease and without taking a single mediation. But today, it is mandatory to visit hospital for health check-up. Almost babies are taking birth in hospital because, people lost coordination with planetary motion in our solar system. Earlier, only few peoples were suffering with BP sugar, but today it is common in most of the people. Day by day people are losing their body strength, mental ability, patience, immunity power, happiness etc. within 20 years we created hell on this earth. It is only because of pollution of Kalana. Which is more dangerous than air pollution, water pollution, sound pollution and any other types of pollution.

The Kalana can be defined as, "Something is there without nothing, in the form of peepul tree's leaf, which is the cause of creation of this universe, is called Kalana!" The universe is arranged in a systematic manner within the Kalana. It is the pure brightness. There is no need of sunlight where the Kalana exist. We may feel burning sensation in sunlight. But in case of Kalana we feel happy. Even sunlight has no capacity or energy to overcome the brightness of Kalana. At the beginning of creation or origin of universe, only pure Kalana was covered the entire Universe. Daily activities of creature made pollution and Kalana was started to cover with darkness. For example: The pure transparent colourless water will get turns into dark or appears in different colour as we add the pollution to it. In the same way, the pure bright colourless Kalana which is looking like white hole, polluted and changed into a black hole. Black hole consists of heavy dense mass or pollution and there is no Kalana in it. Similarly, due to pollution, our surrounding media acting as a black hole. The continuously generated Electrical energy which is part of our regular use, is disappearing in our surrounding media in the form of light and heat. It is not possible to recycle Electrical energy based on the principle of "Law of conservation of Energy". The pollution not only consuming Electrical Energy but all types of energy including stored energy in human muscles, immunity and all our efforts are becoming useless due to pollution. This is how within 20 years everyone lost their immunity, mental ability, control over their own body and mind, quality of food, happiness in life and we lost everything.

Kalana is the actual source of Energy, Knowledge, information and everything in this universe. Actually, there is no birth and death in our life. Here none is taking birth and none is dying completely. The sperm, which already exist, will find perfect media for its development. When it enters into an egg, then starts duplicating itself by receiving the Energy, Knowledge, information and materials from Kalana, which are required for formation of its own duplicate cells. Finally, it will appear in a perfect shape and it is called as birth. Birth or Formation of body in today's generation is, source of creation, source of energy, Knowledge, information and everything will combine together and working in a systemic manner for few days. But in case of death, the body and soul will separate and gain they will not combine together and it is declared as death by society. But this is not complete death, it is just deformation of body. Here, source of creation, source of energy, Knowledge, information and everything will separate, because of not having coordination and cooperation in between them. The living organism should grow day by day, in such a way that, its size and capacity should be equal to Kalana. Developing our self beyond limit to reach or re-join to the Kalana is called real death and appearing in a particular shape directly from Kalana is called real birth. In old generation, many people wish to get liberation from, these fake birth and fake death and to re-join with Kalana. You well known that, for construction of building, we require bricks and bricks are prepared by soil. In the same way, different types of cells are required for the formation of a body and the material required for the formation of body cells will be provided by Kalana. So, I called Kalana is the mother of creation 
and hence onion and potato start growing in kitchen room without water and soil. Because their exist Kalana.

\section{Origin and Evolution of Universe in Kalana}

In the bellow fig-1, at the top left side of the figure, it is shown the process of making buttermilk in village style. Most of the people know it. In the same way, due to the result of stirring in Kalana continuously, bubbles will appear, which are source of creations. These sources of creations are cause for the origin of this whole universe. The stirring process is naturally happening, as our heart beat occurs. The waves generated in Kalana, due to stirring process will makes all planets rotate in Kalana and helps them to move around the sun in our solar system. In the fig-1, it is clearly represented how the Origin and Evolution occurred and it is continuous prosses in this Universe and 24X7 it is occurring in our surround area. As a result of this, the continuously changes occur in the whole universe. In detail it can be expressed step by step as,

1. Waves :The waves are appearing in Kalana continuously due to naturally occurring stirring process. When the waves in Kalana stops, then the whole Universe will end up and we will never find the proof for existence of something in this Universe. Due to appearance of waves in single point and spreading to whole Universe, the Universal time is constant and whole Universal arrangements are in coordination. Universal changes have major impact on the body because body cells and universal arrangement as well as atoms are similar.

2. Source of Creation : The Sources of creations are like air bubbles which are appearing in Kalana. When the waves collides and or overlaps, then the Sources of creations will appear as air bubbles in Kalana, (Here source of creation is like bubble filled with Energy and gives birth to the source of Energy). The Sources of creation act as an Egg and gives birth to the energy source which is living or non-living. This is a continuous process in Kalana.

3. Source of Energy: The continuous stirring process in Kalana will results the appearance of different types of Sources of creations and gives the birth to different energy sources like particle, animals, birds, trees, etc. The energy source which is capable of interacting with Kalana is called as living body and the energy source which is not capable of interacting with Kalana is called as non-living body. Life is challenge of beginning in the state of Energy, Knowledge and wealth. Otherwise, it will destroy completely and re-join to the Kalana or appears in the form of pollution. The beginning and End of life explained with Ex-1 and Ex-2 as, Ex-1:Origin of Life: - I kept, clean and pure Groundnuts, Green grams, Peanuts and Cowpea all in a separate container for observation. After few days different types of pests appeared. They were deferent in each container and not existed before ever in the surrounding media. Here the container filled with Kalana and seeds are source of creation and pests are energy sources. In Kalana, the sources of creation are different for different types of living organisms and non-living things. Wherever the source creation exists, there that particular organism takes birth without the parents. In fig-1 the different energy sources are represented with different colour code.

4. Dependency: In this universe earth is at dependency stage. There are many planets exist with deferent atmosphere in this Universe. Here l'm explaining only about Earth. dependency stage is represented in the fig-1. And hence everything is dependent on one another. The proteins, vitamins and many other materials which are required for the formation of body cell are freely available in the media in form of 0 to 9 colors. When they mixed with the Kalana, then they are fit to form a body cell and the combination of different types of cells will finally appears in a perfect shape like pest, which has its own shape, sense and activities. The purpose of dependency can be explained clearly with this simple experiment.

Ex-2 : End of life:- The water possesses some similar characters as Kalana. If we want to make any doll or idol with mud or soil, we need water. Without water it is impossible to give a perfect shape. The evaporation is also one of the characters of water and it always try to evaporate when it is exposed to atmosphere. If doll or idol made from the water and mud, at the beginning it will have water content and it is smooth. If it is exposed to the atmosphere then the water starts evaporating. As the water contents decreases in the doll or idol, then it will 
become rough (it will die). If we wish, the doll or idol should be smooth (live) and we wish to have water contents in it, then we should add water slowly without affecting it structure.

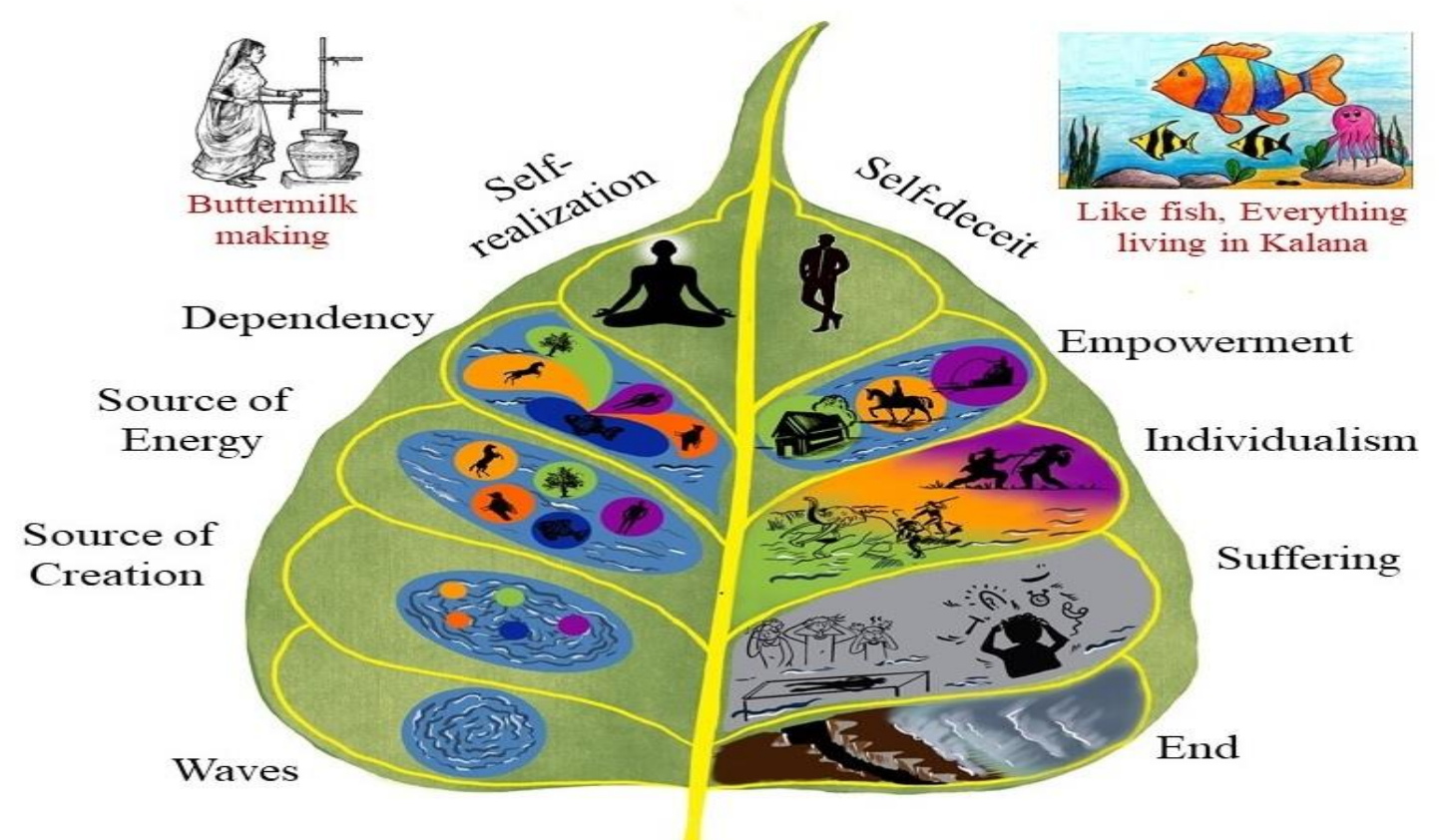

Fig-1 : Origin and Evolution of Universe in Kalana

In this experiment it found that, to keep our body in perfect shape and healthy, it is important to consume food, air and water, etc. Which are the sources of energy and have Kalana within them. It means the food, water air and everything exist in the form of energy sources and source of Kalana. When the stored Kalana, which is in our body, starts evaporating, and body cells fails to extract it directly from surrounding media to compensate evaporated quantity of Kalana, then the troubles like hungry or thirsty appears in our body. Then we feel to eat something and extract the Kalana form it, to compensate the evaporated Kalana from our body and keeps to growth or modification of the body. The consumable materials which are capable of interacting with Kalana are only useful to form body cells. If the materials by mistake, mix with impure Kalana, then they are called as cancers cells, infected cells, useful bacteria, harmful bacteria, virus, etc. Otherwise, the materials will be treated as waste and removed from the body through the digestive system. Simply eating the food with high proteins vitamins is not useful to our body. For healthy life, we should try to interact with source of creation and Kalana.

If the Kalana, evaporates from our body then the organs stop working. Afterwards body hardness will increase and soul loses control over its own body. Communication between one cell to another cell will ends. Which adversely effects the flow of blood and creates more presser on heart. Then Heart fails to push or receive the blood from different parts of the body. Then the heart stops its function. It clearly shows that, when the Kalana exits from the body then the soul will separate from the body. Now a day, it is commonly called as heart attack. Which was not exist in few years back. Due to pollution, the existence of Kalana is rear. If exist, it is not pure and hence in today's generation disease are more. Don't know when it will exit from our body and when we will die.

5 Self-realization: Understanding of how our life originated or started and how it will end is nothing but self-realisation. The important and challenging task is avoiding the dependency. As I told earlier, the particle which is capable of interacting with Kalana, is a live particle. It may or may not have the characters like sense, growth, reproduction etc. here main role plying by Kalana.

The particles like proteins, vitamins, and many other things are the energy sources and possess their own source of creation and also have a capacity to interact with Kalana to form 
a cell. If Kalana is the main source of origin of cells, and cells together systematically arranged to form the entire body, then each and all cells have their own function. Letting each cell to do their own function and not commending them to do as we wish, each and every time is also the self-realisation. If we self-realised and let all cells to work freely, then there is no need to depend on others. Each and every cell fulfils their own requirements from their own source of creation.

6. Self-deceit: Here in this universe, if the particle is capable of interacting with Kalana then it will develop its own source of creation and converts itself into a live cell (Source of Energy). Otherwise, it is inactive. If all particles have its own characteristics, whether it is capable to form body cell or not, then there is no necessary of forcefully holding or controlling of our body parts or particles exist in our surrounding nature. The person who is not known about his own body characters and fails to interact with Kalana then he will never understand anything or fail to sense the universal arrangements, then he will be called as Self-deceit. If the person believes that, the body is everything for him and he is owner of it, then he will start to cheat himself by giving commands to his own body each and every time. All body cells have their own source of creation and source of energy. But isolating them from Kalana and forcefully controlling is foolishness. It is egoistic nature. Not understanding reality, behaving as our own wishes and having own life style will breaks the valuable relationship between our body cells and Kalana. The person, who is self-deceit he will destroy the naturally available his own source of creation, and creates his own source like soul, mind, intelligence and start suffering because of his own activities. As the person separates from Kalana, his dependency increased.

7. Empowerment: the person who is separated from Kalana and destroyed his own source of creation and source of energy then he stared to depend on other source of energy to fulfil his wishes. Due to his intelligence, he became not only the owner of this Universe but also, he called as creator of this Universe i.e., Lord of the world. But actually, Kalana is main reason for creation of everything in this Universe. Instead of trying to attain "Zero Energy" state, he started to develop different types of energies by miss using natural resource of Kalana. Finally, this leads to increase in pollution in atmosphere and that pollution start accumulating on every object from the atmosphere. As the pollution increased and human body pollutes then foolishness increases due to inactive senses. Means due to pollution sense were unable to sense the universal changes and everyone fails to act according to the situation. And hence the following changes occurred in society as,

- The people become over dependent.

- People separated from nature and created their own society by utilising naturally available resources.

- Due to intelligence and application of mind, people created new things which are not available in nature.

Because of over dependency, instead of following nature or Kalana, people started to follow their own set of rules and regulation and started to rule this world.

8. Individualism: Because of having own way of thinking, own intelligence, everyone started to express their own useless feelings, then miss understanding increased in relationship. Hence, false feelings are destroying peace of mind. People became arrogant, he/she lost coordination and cooperation with his own society. The people started to do illegal activities like killing animals, birds, cutting trees and increasing pollution. Due to increase in pollution, day by day human lost humanity and intelligence. He was unable to sense the changes in Kalana or Universe and he lost the truthfulness. Falls feeling and illegal activities results the imbalance in nature and arrangement of 0 to 9 colours in whole universe. Then natural phenomena like earth quick, volcanoes, started to occurs to balance the nature.

According to Morden science human body made up of $75 \%$ of water and many other elements, chemical compounds, etc. but there is no space or proof for existence of our own soul in our own body. It clearly shows that, our soul and our feelings like Happiness, sadness, excitation, depression, foolishness and many other types are floating in Kalana in our own 
body and not visible physically to anyone. So, if Kalana is pure then only all our feeling and our soul will be pure and we will be happy otherwise we will feel to commit suicide. Means we don't like to be in touch with our own body or our body cells don't like to stay with us as we are engaged with pollutant and separated from Kalana. In practical we feel happy only if we go out of polluted environment. Because if we stay in pollution free environment and at the place where there is rich Kalana, then our body cells will directly interact with Kalana and fulfils their own requirements and also makes us happy.

9. Suffering (Morbidity): When the person unknowingly destroyed the source of energy by means of illegal activities like killing animals, birds, cutting trees, etc., then the individual source of creations as well as source of energy mixed with one other and pollution increased. Due to high level of pollution, and the mixing of sources of creations with one another, diseases started to appear. If the man, who takes birth in one source creation will enters into the other source of creation, which is giving birth to Elephant, then he starts suffering with a disease. Because the human body cells not able to adjust with the other source of creations, which is giving birth to Elephant. As we feel happy and comfortable in our house but not in friend's home. This is how today we are getting disease in the name of birds, pigs and other animals. As we are suffering by the entry of bacteria, virus and other organism into our body cells. When they lost their won source of creation then they are utilising human or source of other animal for their growth.

Ex: If I destroy the others home then he asks shelter in our house, it is like punishments.

As the pollution increases then source of creation and existence of Kalana will reduce. Then the material required for the growth of body cell will never be available. And also, energy will decrease in muscles and only waste mass will accumulate in body. Waste mass means pollution and due to pollution body cells are not able to perform their function. Communication between cell to cell will interrupts and hence the person becomes inactive, lazy, feels boring, falls feeling increases, coordination between body and mind will breaks up. In most of the case the person is unable to guess "what to do next?" Then the person fails to sense the situation and his efficiency in work decreases.

10. End: When Kalana disappears then the coordination and cooperation between any particles will ends up. Then everything starts miss behave and destroy themselves. This is the end of everything whatever exists in this Universe. Nature, always try to achieve equilibrium state, so natural phenomenon will occur to balance the arrangements of 0 to 9 colours in universe.

\section{Modernisation With Wrong Concepts}

Today's generation is developing with more advanced technologies. Every educated person knows that pollution is harmful to his health. Instead of being natural friendly, he is also involved and busy in doing pollution. Here everything matters life style. Few years back people were nature friendly. They were celebrating different types of festivals depending on the changes in nature. Nature was the part of their daily actives. Even today also the person who is natural friendly, he will be happiest person in this world. Because, he knowingly or unknowingly respects and come in touch with source of creation as well as with Kalana. Till today all scientists fail to identify the originality of Universe, Universal creatures, surrounding media or space. Without proper understanding the actual concept of Origin and evolution of Universe, they conducted most of the experiments only on polluted layer of Kalana and forgot the actual source of energy and source of creation. Actually, all particles, animals, birds, trees, everything will receive the energy from this Kalana only.

Modern scientist may conduct may experiments and analysed everything whatever exist in this nature. But most of the experiments and scientific researches conducting only on three sates of matters i.e. Liquid, Solid and Gas. These are all by product or natural waste of live bodies. Initially even water and air also not exist in this universe. Life on the earth appeared not because of existence of water but water present on the earth only because of presence of live bodies. Birth of above three states is interesting and it is explained as follow. As you know there are two types on energy 1. Potential Energy, 2. Kinetic Energy. But all the Energy states will originate from "Zero 
Energy" state i.e. From Kalana. Hence there is "Zero Energy" or "no energy" exist in this Universe. And the existing energy state, which may be in whatever form, will try to vanish itself. Means every Energy, it may or may not possess the infinite sate of Energy at some point in its life time but finally fall to the "Zero Energy" state.

Similar case will repeat in all object or particle whether it may live body or died. All particles or matters may possess two states of energy but finally and definitely they will acquire "No Energy" state. Because everything in this Universe always try to acquire the state of equilibrium, means "Zero" state of Energy or "No Energy" state and hence there is another state of energy exist in this Universe as,

1. Potential Energy

2. Kinetic Energy

3. Zero Energy or No energy or Kalana.

Everything in this Universe starts with Zero Energy level and then develops its own energy, it may be Kinetic or Potential Energy and it can be expressed as,

$$
\begin{aligned}
(\text { Object(Energy }))= & \left(\begin{array}{c}
(-) \text { Receives the Energy from } \\
\text { Kalana } \\
\text { during formation of Body }
\end{array}\right)+\left(\begin{array}{c}
(+) \text { Develops } \\
\text { its own Energy }
\end{array}\right) \\
& =\text { Finally attains the Zero Energy state } \\
& =\int_{-\infty}^{+\infty}(\text { Object }(\text { Energy }))=0=\text { Kalana }
\end{aligned}
$$

At some point the energy of an object is "Zero" and then the object starts to develop its own energy with the help of Kalana which is always possess no energy.

Ex: Atoms have

1. Protons have positive charge

2. Electrons have Negative charge

3. Neutrons have No charge or zero charge

But neutrons help for chain reaction in atomic bombs and release extremely high energy.

And hence every object will gain the energy from "No energy" state or "Zero energy" state will supply the necessary form of energy to the object and after reaching final state or infinite state, again it tries to attain "Zero Energy" level only i.e., state of equilibrium.

Note : There is no neutrons in atoms. The presence of Kalana in atoms is noticed as Neutrons.

In case of existence of Pollution, as the energy stored in live body, may be kinetic or potential Energy tried to attain the state of equilibrium or "Zero Energy" level and Kalana started to Evaporate from the body then it releases the waste/pollutant from its own body in the form of Solid, Liquid, Gases and many other things. In that water is also included.

$$
(\text { Object(Energy }))=\left(\begin{array}{c}
(-) \text { Receives the Energy from } \\
\text { Kalana } \\
\text { during formation of Body }
\end{array}\right)+\left(\begin{array}{c}
(+) \text { Develops } \\
\text { its own Energy }
\end{array}\right)
$$

=Finally attains the Zero Energy state + Water (liquid) or Gas (or any other kind mass)

Ex: The swatting in live body release water content.

Note : 1) There is no water in any live body. the presence of Kalana is noticed as water. But the water, what we drink will exit from the body in the form of urine. Swatting is the chemical reaction in between Kalana and body cell.

2) when any person or animal feel sad or cry then water will release from eye because eye is source of Kalana in live body.

3) Here in one molecule of water, there are two hydrogen and one oxygen and $97 \%$ Kalana is there.

$$
\mathrm{H}_{2} \mathrm{O}+97 \% \text { Kalana=water in the form of liquid }
$$

4) In absence of Kalana, the water will pears in the form of gas. 
When the live body release wastes like Solid, Liquid and Gases to the space then Kalana will pollute. This pollution acts like mass. During interaction with Kalana, knowingly the particles acquire the mass from surrounding media (pollution will enters into its body) and then particles started miss behave. Here particles may be any objects or animals, Bird, human or any other kind of live organism. Because, the pollution acquires the gap between the particles and separates them. As soon as the communication interrupts between particles like atoms, body cells or humans, then the synchronisation and coordination between them will breaks up and hence, particles start to miss behave.

Ex: Due to increase in pollution, there is no coordination and cooperation between human relationships. Here, invisibly another three states of maters exist in this universe. They are,

1. Kalana

2. Source of Creation

3. Source of Energy.

All these combined together to give birth of whole Universe and whatever exist in this Universe. At the beginning only Kalana exists, waves were created due to natural stirring process, the sources of creations appeared like air bobble in Kalana, then in these sources of creation, the particular living organisms and non-living things took birth as a source of energy. For better understanding I compared to all these as follow,

- Mother - Kalana. Which gives birth to everything.

- Mother womb - Source creation. Birth place or climate where everything can initiate its life.

- Baby - Limited source of Energy, knowledge and information. Everything actually acquired by Kalana.

Here I found some modern experiments with errors which I learned in my school days and did research on them and found exact reasons:

1. At the beginning it is noticed that, the sun light consists of 7 colours. Later in absence of sun light, I think many people observed the 7 colours. Even I saw 7 colours of spectrum at night time in street light and also while riding bike, in the head light of car. And same experiment I conducted by using the cooling glass at night time, in absence of sun light and I found spectrum of 7 colours. It is shown in Fig-2. In reality, there is difference between sun light, street light, car head light and mobile screen which I used to conduct the experiments but the media is same. It means, the colour spectrums will never present in sun light or any other light, but all colours arranged systematically in our surrounding media.

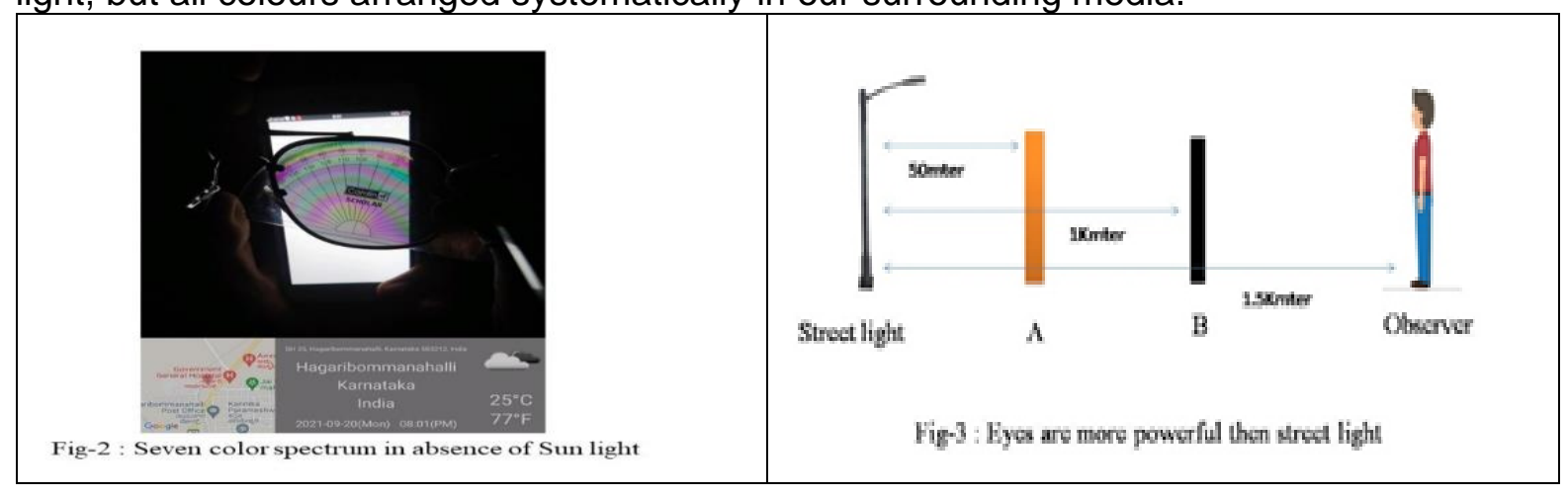

2. There exist a 0 to 9 colour in our surrounding media i.e., 10 colours. Black, white, Red, Orange, Yellow, Green, Blue, Purple, Violet and Kalana. The colour of Kalana is colour less and all colours together created this Universe. Kalana initiates the formation of objects and then other colours replace the Kalana and forms the solid objects. as colour less water will become solid when Kalana is replaced by white colour. These colours don't possess any wave length, mass and have infinite energy. The presence of 7 colours in colour spectrum is due to the disturbance set up by the planetary motion in solar system. If the properties of 0 to 9 colours is identified then it is possible to create the mathematical model of the whole universe.

3. The lightning stroke is not due to collision of clouds and releasing or discharging of stored charge from clouds to ground. Rain water is non-conductor of electricity and hence there are 
no charges in clouds. If it is true, then it is not possible to build outdoor Electrical grids. But almost Electrical grids are outdoor type and working in good condition even in rainy season also and rain water is not affecting insulation system of Electrical equipment means, there is no charge in clouds or rain water has no capacity to hold the charges. But lightening is due to explosion of particle present in the atmosphere. During rain, the particle in the atmosphere will mix with water and increase their size. As the size of particles increase, then the pressure in atmosphere will increase due to compactness and most of the particles will explode because of high pressure in less volume, by releasing tremendous stored energy.

4. The concept of vision is also wrong. The light may reflect back from the surface of object but the reflected beam will not reach to human eyes. Still the object is visible to our eyes. In fig3 , it is shown that the observer is $1.5 \mathrm{Km}$ away from the street light. The light falls on object$A$ and it is visible to observer. But the object - $B$ is in darkness. Here the light ray travels only up to $50 \mathrm{mts}$ and still the light is visible to the observer who is standing $1.5 \mathrm{~km}$ away from the light. Because eyes possess their own source of energy and the energy emitted by eyes falls on the object and reflects back. So that the objects are visible even in absence of light also. Our eyes act like transmitter and receiver of light singles generated by own source of energy. But the polluted media which is acting as a black body, will consume the signal emitted by eye then the object - B which is in darkness is invisible. In Fig-3: The ray emitted by eye is stronger than the $100 \mathrm{~W}$ bulb. Because Eyes and Brain are filled with Kalana. Almost all people close their eyes during prayer to prevent the wastage of energy for single moment. Behalf of wasting energy by looking here and there, it is used for own development. When you close the eyes, the energy stored in eyes will circulates in your own body and you feel happy. Trained eye beam has a capacity to break or destroy anything. The light beam emitted by eyes are stronger than the sun light. And hence old people are still using black thread or black cloths to escape them self from the vision of bad person. Eyes are also associated with natural black body in it called as "Pupil". Pupil not allows any types of outer radiations or light to enter into the eye. Because eyes were very sensitive sensor. We feel burning sensation due to radiation of sun light. Nowadays the skin colour changes due to pollution. So, if the sun light or any other harmful light enters into the eye each and every time, then eye will burn out within few days. Hence entry of sun light and all other lights are prevented by natural black body pupil.

5. Sun, only emits the energy radiation from its outer surface and hence the radiations emitted by sun has no particle nature. Actually, the polluted dust particle present in the media will heats up due to the radiations emitted by sun and behaves like hot particles, which are emitted by sun and scientist called these particles as photons. Photons are the particle present in media or scattered in media and heats up due to sun radiations but not the sun light behaves like photons.

6. The behaviour of interference and diffraction of light is only due to the presence of Kalana. Means scattering of particles due to light or reflection of light is due to presence of Kalana in media. As when you through stone in water then waves will appear on the surface of water but not the stone will possess wave nature.

7. Even though each particle associated with its own energy source, in today's generation we are feeding external energy to activate the atoms or to move electrons. But this was not the case in ancient time. The people developed advance technologies based upon the universal truth. And everything was accurately working without feeding the external energy and without power loss they were able to travel in whole universe with flaying machines. But today we are using fuels and also generating huge amount of Electrical energy and wasting it in media. Due to pollution, not only our media but also everything acting as a black body and destroying or consuming energy sources. In this case "Low of conservation of energy" is totally wrong. If it is true then pollution will never occur after burning of fuels.

8. Energy and mass are not interchangeable. Energy can be converted into mass or energy source can acquire a mass naturally but the conversion of mass into energy is not possible. Means stored energy in the mass may be released but mass itself will never convert into energy. When the mass loses its energy then it will act as "anti-energetic material" (the mass with no energy), which are commonly called as pollutants. This anti-energetic material will destroy the other source of energy. This is how the pollution killing everything. If the mass of 
the particle increases then its stored energy will decrease or the particle will lose its own source of energy.

Ex: 1. stored energy in the wood can be utilised to create fire but when the wood loses its stored energy completely then it will release waste mass as ash. Which is, anti-energetic material. You can't convert that mass in the form of ash into energy source.

2. In other case, stored energy in stone is less than that of diamond. Because the stone is filled with mass and due to compact structure of diamond there is less mass. And hence its value is also more in society because the content of Kalana is more in Diamond.

9. Here whole Universe is moving with respect to the changes in Kalana. In other words, the whole universe as well as the changes in our body, motion of electron in atoms, motion of planets around the sun, movement of sun itself and everything is in relative motion with respect to Kalana and if the changes in Kalana stops then every activity will stop.

10. If my heart beat and pulse rate are same then the time in this entire universe is same. It may be called as universal time. Because, my body is in relative motion with Kalana and also there is a similarity in my body and universe. Each object in Kalana is moving with its own speed and hence there is a time difference in all but Universal time is constant.

11. If the creation is pure and the particle or any object to be considered as the source of energy, then Mass of the particle must be zero $(m=0)$ and it should behave like waves. As the 7 colours in the media behaves like waves and spread in Kalana. In creation mass means the pollution acquired by the body or particle or any object. As the mass increases, the body loses natural source of energy and becomes inactive or lazy.

Ex : We notice that the ancient architecture or temples like Hampi in Karnataka, built with large well-structured stone. Because in ancient time due to less pollution the gravity is also affects less and people were able to lift larger stones easily as any heavy object or material lift in water easily. Here Kalana is compared to water for better understanding.

12. The field which gives mass to any object is the polluted layer of Kalana. The darkness which is visible all around us is also polluted layer of Kalana. Actually, our surrounding media is brighter and we no need any extra lighting arrangements or sun light to see any objects or particles if we clean our surrounding media. Due to pollution the darkness covered all around us and hence $24 X 7$, we are living in darkness. Sun light is not the perfect light to lead the life. We should get the pure brightness from Kalana only to get peace of mind and for success. "Angels" is looks brighter because of presence of Kalana in their body.

13. In ancient time, when the pollution was less, the people were travelling in the speed of mind without machine. There is a word "Angel", "God", in dictionary means they were existed. All dictionary words are valuable and each word is outcome of Universal arrangements. Angel has body with no mass and they were associated with wave property.

14. Mitochondria are called as power house of cell. The power stored in mitochondrial must be Kalana but not the energy extracted from another object. If Kalana is present in body cells then person will glow always and he/she won't feel to eat or consume any food. That person is called as "Angel", "God!"

15. Loss of immunity power means loss of own energy source. Due to pollution, energy sources are disappearing and created challenging diseases in today's generation. Simply by eating will never fulfils your body requirements or helps for the growth of your body. Here everyone should get the energy from Kalana only. If it not supports for the growth of cells then disease will appear.

16. If you believe that the body is made up of five elements like Earth, fire, water, air and space. I'm trying to explain the life much before the existence of all these elements. Here the Akasha or space gives the definite boundary of energy for any object but if you wish to get liberation you should break that boundary and expand yourself beyond the limit to reach the Kalana.

17. Every live body has Kalana, source of creation and itself act as source of energy. Source of creation helps for reproduction.

18. Earth is live body because it interacts with Kalana. Earth have Kalana, Source of creation, and itself is the Source of energy. Before polluting the earth, it was glowing like star. Due to pollution earth lost its source of energy and artificial solar system is built by ancient leader who ruling this earth to have better life. At the beginning of origin of Universe, there was no darkness on Earth and no solar system. 


\section{Effect of Pollution}

Due to human activity, ineffectual change in Kalana is called as pollution. It may be addition of foreign particle or modification of Kalana itself. Each and every activity of living body will create the vibration. The vibrations produce the imbalance in 0 to 9 colours and in Kalana is the main cause of pollution. Any living body which possesses the wave property will act according to the change in Kalana or it follows the principle of truth then it won't produce any pollution but the living body which possess the particle nature and acts with its own intension, will produce the pollution by modifying the existing shape of Kalana. Which is very dangerous. Due to pollution of Kalana, everything becomes inactive and loses coordination and cooperation.

Ex: In today's generation most of the people act according to their own intension and lost the peace of mind. Challenging health issues are appearing.

\section{Effect of pollution on human activities}

The whole universe is arranged in Kalana in systematic manner. Small change in Kalana effects the whole Universe or the Universal changes refracts in Kalana. The truthful person always tries to act according to the change in Kalana or Universal change. It is very interesting, do you know? Most of the time, we speak without thinking. Almost everyone does the same. The conversation between two kind hearted persons is fluent and the words will come out from the mind automatically. The person who is truthful and kind hearted he/she will never think before speaking. $\mathrm{He} / \mathrm{she}$ simply sense the Universal changes and speak fluently with no worries, no doubts and hesitations. Here in this interaction every incident and situation are based on the Universal arrangements and changes occurring in the Universal arrangements at that time. So that we speak and we act to balance the Universal changes. The outcome of Universal arrangements is called "truth" and "truth" has its own significant value in society and everyone expect truth and tries to be a truthful person.

In Fig-4 A: There is no change in Kalana between two objects and hence no matter to discuss or to act.

In Fig-4 B: There is a change in Kalana between two objects and hence there exist an information to discus and to act accordingly. The change in Kalana will produce the waves and those waves will generates the sound. Hence the objects interact with sound or language which
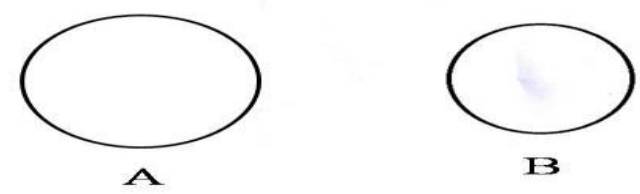

13
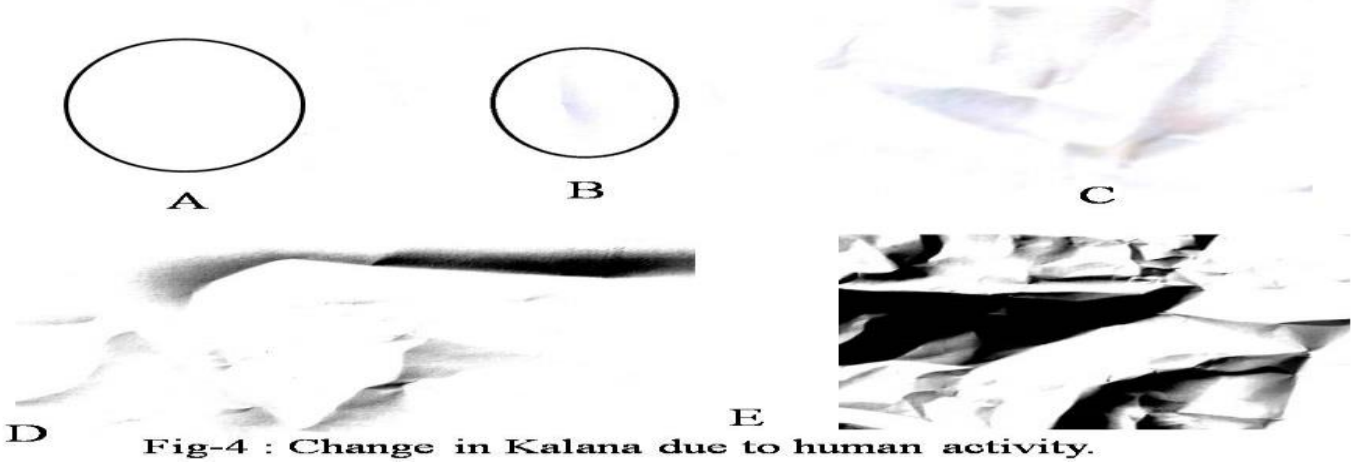

is in synchronise with the waves produced due to change in Kalana. If the waves produced by object and change in Kalana are same then the object speaks truth and it is coordination with Universal changes.

In fig-4 C: There is a large change in Kalana between two objects and hence there is a subject to discuss and work on it, to balance the Kalana. If objects do any mistake, then more pollution will occur. Both should act carefully. In general people simply say that "we should have common sense" to balance the situation. Otherwise, we will fall in trouble. Note that our ancestors were more advanced. They were able to calculate the area of change in Kalana to predict the future or the action to be performed to balance the change in Kalana and to avoid pollution. In my childhood I heard that the animals and even the aboriginal tribe people were able to sense the natural phenomena.

In Fig-4 D: There is large change in Kalana between two objects. But the problem is, the change in Kalana is covered with darkness and it is impossible to sense the information or subject 
to take decision. Pollution, that appears in Kalana will kills the peace of mind, coordination and cooperation between two objects will breaks. If the situation is not balanced then the two objects will fight each other due to misunderstanding. The same thing happening in between so called well educated couples and diverse cases are increasing in today's generation. We may well, educated but not have a capacity to balance the situations because we don't know anything about Kalana.

In Fig-4 E: There is heavy pollution in Kalana and difficult to survival. In this situation everything will misbehave. Forget the interaction between two objects, the individual object will struggle for survival. Its own body and mind synchronisation will break up and starts to act like mental and hence pure Kalana is every important to maintain good relationship and to have healthy society. Few years back, people are sincere and truthful. Everyone followed the natural changes and celebrated the festivals according to the changes in solar system. Even today also few of the religious community peoples acting according to the changes in solar system. But today most of the people acting according to their own false feelings because of ego and also our technologies are not based upon the "principle of truth!" So, everything has its own side effects and harmful to society as well as to our life. Hence today's generation is suffering with many diseases.

If the people fail to act according to the change in Kalana then the pollution will increase and Kalana will covers with more darkness. Wherever the darkness exists, there exists an imbalance in everything and that place is totally corrupted. And again, people fail to sense what is happening in Universe, his/her sense will become inactive and fall in trouble. Challenging health issues will occur and again the pollution will increase day by day. Due to pollution Ego, short temper, mind related problems will increase.

\section{Effect of pollution on Earth.}

In this Universe source of creation appeared first and then the source of Energy. Every object is source of energy and even our Earth is also the source of Energy. Earth gives birth to the plants means it is live body. The Earth consist of Kalana, source of creation and source of Energy and hence it gives birth to the plants when seed falls on it. The particle which is the source of energy will glow like stars. But we see the darkness everywhere on earth and we are leading life with the help of sun light. You believe it or not at the beginning of Origin of Universe, the Earth was glowing like star and there was no sun or no moon. Totally solar system did not exist. Not only the Earth, every living and non-living body had brightness because everything was filled with pure Kalana. And external light was not necessary. Even today we find the emission of light from the live body in thermal image but it is not so bright and hence we have weak body and short life span with challenging decease as compared to old generation.

When the darkness covered whole world then the life on Earth and other planets was at the stage of end. For survival and to overcome the problem of darkness, the leaders of different planets as well as leaders of Earth planned to clean the Kalana and the collected pollution or pollutant is used to build solar system in a systematic manner. Means the pollution or pollutant is recycled to create sun as artificial light to give brightness to the earth, moon and other planets to control the motion of earth as well as activities of life on earth. The arrangement of solar system is identical to human body cell. Because the leader just copied the nature's creation and built the wonderful artificial solar system, in that some species lost their life, because of changes in environment on earth and new species took birth. Now solar system is acting as a moulding container and has a major impact on every life which takes birth on Earth. Means while arranging the body cells in particular manner to form a perfect body structure, arrangements of planets in solar system also have its own impact and decides the each and every activity. Because, body cell components and planets in solar systems are related and also motion of planets will helps to the movement of food in digestive system. 
The comparisons between solar system and body cell and atoms are as follow:

\begin{tabular}{|c|c|c|c|}
\hline$\#$ & Human body cells & Atoms & Solar system \\
\hline 1 & There is a nucleus & Atom also has nucleus & $\begin{array}{l}\text { In solar system Sun act as } \\
\text { nucleus }\end{array}$ \\
\hline 2 & $\begin{array}{l}\text { Genetic materials are there } \\
\text { in nucleus }\end{array}$ & Protons are there in nucleus & $\begin{array}{l}\text { Active chemical compounds } \\
\text { are there in Sun and create } \\
\text { centrifugal force of attraction. } \\
\text { So that all planets should rotate } \\
\text { in their own excise. }\end{array}$ \\
\hline 3 & $\begin{array}{l}\text { Cell has a cell membrane } \\
\text { and filled with cellulose }\end{array}$ & $\begin{array}{l}\text { Atom has boundary and filled } \\
\text { with energy. }\end{array}$ & $\begin{array}{l}\text { Solar system also has its own } \\
\text { boundary and filled with its own } \\
\text { atmosphere }\end{array}$ \\
\hline 4 & $\begin{array}{l}\text { Other particles of cell are } \\
\text { floating in cellulose }\end{array}$ & $\begin{array}{l}\text { Electron are moving around the } \\
\text { nucleus with the help of energy } \\
\text { which possess wave property }\end{array}$ & $\begin{array}{l}\text { All planets are floating in their } \\
\text { own atmosphere and rotating in } \\
\text { their own access just like fish } \\
\text { swimming in water. }\end{array}$ \\
\hline 5 & $\begin{array}{l}\text { All cells associated with } \\
\text { different types of cellulose. } \\
\text { That makes the difference } \\
\text { in cell structure. }\end{array}$ & $\begin{array}{l}\text { All metals are associated with } \\
\text { different types of energy. } \\
\text { Hence different types of metals } \\
\text { are available. }\end{array}$ & $\begin{array}{l}\text { There are many solar systems, } \\
\text { galaxy with different types of } \\
\text { atmospheres. }\end{array}$ \\
\hline 6 & $\begin{array}{l}\text { Cellulose decides the type } \\
\text { of formation of elements in } \\
\text { the cell }\end{array}$ & $\begin{array}{l}\text { Energy, present in the atom } \\
\text { decides how many numbers of } \\
\text { electrons, protons it can hold } \\
\text { and also type of bound } \\
\text { between the protons and } \\
\text { electrons or between atoms. }\end{array}$ & $\begin{array}{l}\text { Atmosphere decides types of } \\
\text { Objects, life and everything in } \\
\text { that solar system. }\end{array}$ \\
\hline 7 & $\begin{array}{l}\text { Changes in body cells } \\
\text { occurs with respect to } \\
\text { change in Kalana }\end{array}$ & $\begin{array}{l}\text { Motion of Electrons occurs with } \\
\text { respect to change in Kalana }\end{array}$ & $\begin{array}{l}\text { Motion of planets as well as sun } \\
\text { occurs with respect to change } \\
\text { in Kalana }\end{array}$ \\
\hline
\end{tabular}

Ancestors had good sensing capacity, without the use of external equipment they were able to realize and visualize anything from anywhere. Today's generations lost the sensing capacity and have artificial satellites to improve the life style. As we have the artificial satellite for simplify the life, our ancestors created artificial solar system to lead the life. If we are not in coordination with planetary motion then our body activities will change.

Ex: 1) Few years back normal deliveries are common but today $\mathrm{C}$-section deliveries are common.

2) Digestive system not working properly. Indigestion is common problem.

\section{Goal of Human Beings in Kalana}

Goal of human life is to avoid dependency and act as source of energy, Knowledge, information and possess wave properties. The person who possesses wave properties he/she act as angel and travel in the speed of mind and can acquire any shapes. Actually, consuming food is offence. If body is already having a capacity to develop everything, whatever may be its requirement by interacting with Kalana then what is the necessity of feeding external food? Even if we feel to eat something then we should take only soft food but not the food with high nutrition and proteins. Because, earlier purpose of consuming food is only to extract the Kalana from other source but today we forgot the Kalana or energy and thinking only about proteins, vitamins and nutrition. Adding pollution to our body will kill our own energy source and increase foolishness.

Kalana is like a gum and we need it for good relationship. Just imagine the life without coordination. If there is no coordination between couples then they always fight each other and finally apply for diverse. Same case exists between body, mind and soul

- If there is no coordination between body and soul then you feel to commit suicide.

- If there is no coordination between your body and mind then you realize the dreams. When body not supports for your work then mind will try to do that work alone and your body experience that work in the form of dreams. If the mind is dominating the body, then the person will become mental. 
The soul and mind are floating in Kalana around your own body. The body is like nest built by soul. What you do with body is physical life and what you do with mentally is spiritual life. The dreams are spiritual life of you. Cooperation and coordination in colour code are very nice. We should learn from colour spectrum. All colours have a good relationship and combine together to forms different types of colours. Actually, colours are also living body because they give response and interact with Kalana but possess wave property. In normal condition the colour spectrum not invisible but helps all spices to have wonderful life. Look at the nature how it is beautifully decorated because of colours. I can give the proof for existence of God as the colours exists in our media and the God also have the properties like colours but invisible.

Nowadays the world "God" is restricted only to dictionary and in realities there in no God. Because in today's generation none knows what is Kalana and how make use of it for better life. But in reality, as money make a Beggar into a milliner and similarly the Kalana make an ordinary person to the "God". The person, who have money is called rich person, he may or may not be successful in his life. But the person who knows the use of Kalana then he may be called as lord of the whole universe. Because he is the most successful person in this world and he can control the whole universe with the help of Kalana. At least people should act in coordination with planetary motion in solar system for better life.

\section{Conclusion}

The Kalana is more valuable in our life. It gives birth to the sources of creation and source of creation gives birth to source of energy. Each and every life, particle, Element, whatever which is visible and exist in this Universe are the sources of Energy. Energy source may be available everywhere but the sources of creation are rare. We should not pollute Kalana. Because, the pollution increases the accumulation of waste mass and it will partially or completely destroy the sources of creation results in appearance of challenging diseases. People are saying "save tree", "save water", "save river", "save yourself" but we should "save Kalana". Because, Kalana is real source of Universe, Energy, Knowledge and all information. If you pollute Kalana or separate from Kalana then you will become lazy, inactive, fails to sense the Universal changes and feels to commit suicide. Due to pollution, Kalana covered with darkness and $24 X 7$ everything here is living in darkness. In sunlight only few senses are active and rest are inactive. Kalana has major impact on each and every activity of our body, growth of cells and health. Hence, I request "Save Kalana" for better future. If a person practically knows the meaning of truth, Origin and Evolution of Universe, then he may behave with respect to time sense. And he will be called as truthful person. Then our society will be peaceful and healthy. But in today's generation, there is no value for truth. There is no coordination in society and no synchronization between body and mind and also in-between activities of people and planetary motion in solar system. So, expectation and incidents are different and many people fail to get success. Today none have the capacity to sense the universal arrangements before speaking and working. All dictionary words and number systems are outcome of Universal arrangements and have their own practical meaning and significance then Universe have a definite boundary and hence any changes in Kalana reflect in whole Universe.

Knowingly or unknowingly if you pollute the source of creation then you will never receive the good quality materials, required for the formation of body cells and fail to receive the good information to lead the life. Then you will start suffering with verities of disease by losing control your own body and mind. Hence, because of pollution of Kalana. Today's generation is suffering with new types of disease and many people are failing to lead the life even though having all facilities and they feels to commit suicide. Earth is live body please give respect to it.

\section{References}

1. Class room teachings.

2. "Something is there without nothing" International Journal of Engineering Science Invention (IJESI) ISSN (Online): 2319 - 6734, ISSN (Print): 2319 - 6726 www.ijesi.org ||Volume 8 Issue 07 Series. II || July 2019 || PP 06-07. 